\title{
5
}

\section{The Canberra Plan and the Nature of Law}

\author{
TORBEN SPAAK ${ }^{*}$
}

\section{Introduction}

The analysis of fundamental legal concepts, such as the concept of law, the concept of a legal norm, the concept of a legal duty, the concept of a legal right, or the concept of legal validity, is a central jurisprudential task, so the question of the proper method for analysing concepts should be of considerable interest to jurisprudents. In most cases, the aim of the jurisprudent is simply to elucidate the concept in question, since (he reasons) a clear view of the structure and content of at least fundamental legal concepts will be conducive to clear thinking. But in some cases, especially in the case of the concept of law, the analyst is typically interested primarily in the underlying phenomenon, that is, the property or properties that correspond to the concept thus analysed. Thus it is that an inquiry into the nature of law is typically considered to be precisely an inquiry into the nature of law, the phenomenon, not the word or the concept 'law'. For example, some of our most prominent jurisprudents who have been concerned with the question of the nature of law ${ }^{1}$ have approached this question by way of an analysis of the concept of law. And in doing that they have clearly aimed at an understanding of law, the phenomenon.

\footnotetext{
* Professor of Jurisprudence, Department of Law, Stockholm University. I would like to thank Pawel Banas and Jaap Hage for helpful comments on the article and the participants in the workshop on the methodology of legal philosophy in Edinburgh, 2 June 2015, as well as the participants in the workshop on the philosophy of legal philosophy in Crakow, 22-23 May 2015, especially the designated commentators (Pawel Banas in Cracow and Silvan Wittwer in Edinburgh), for helpful comments on an earlier version of the article. In addition, I would like to thank the participants in the advanced seminar in practical philosophy in the Department of Philosophy, Uppsala University, especially Jens Johansson, as well as my jurisprudence colleagues in Uppsala, Åke Frändberg, Cyril Holm, and Lennart Åqvist, for helpful comments on an even earlier version of the article. Finally, I would like to thank Robert Carroll for checking my English. As always, the responsibility for any remaining errors and imperfections remains solely with the author.

1 See Hart (1961); also Raz (1994) and Alexy (2008).
} 
I can see at least three alternative approaches to the analysis or elucidation of legal concepts, be they fundamental or not, namely, conceptual analysis in the classical sense, explication (or rational reconstruction), and ideal-type analysis. But while either of the two latter approaches may often be useful in a legal context, it seems to me that it is only conceptual analysis in the classical sense that can be correlated in a meaningful way with an inquiry into the nature of the underlying phenomenon. For both explication and ideal-type analysis aim to construct something new — the so-called explicatum and the ideal-type, respectively-rather than to find something that already exists. But, as is well known, conceptual analysis in the classical sense is in some ways a rather problematic enterprise ${ }^{2}$ and jurisprudents have therefore reason to look for alternatives to it.

In this chapter, I shall consider a method for conceptual analysis which has been called the Canberra Plan ${ }^{3}$ and which might perhaps be conceived as an alternative approach to conceptual analysis in the classical sense. The Canberra Plan is not, however, aimed primarily at the elucidation of the relevant concept, but at the metaphysical question of identifying the descriptive (or natural or physical) property that corresponds to the concept. ${ }^{4}$ The idea of the Canberra Plan is, more specifically, (a) to clarify the import of the concept by reference to the role the concept plays in a network of concepts, principles and claims; and (b) to investigate and see what, if any, descriptive property corresponds to the concept thus analysed. What I want to do in this chapter, then, is first to introduce the Canberra Plan and give some consideration to its advantages and disadvantages and, secondly, to apply it to the concept of law, in order not only to clarify the import of this concept, but also to find out what, if any, descriptive property corresponds to the concept.

The question of what descriptive property, if any, corresponds to the concept of law should be of considerable interest to jurisprudents, not only because the metaethical question of whether legal properties are descriptive, or even natural or physical, is generally interesting, but also because the existence of such descriptive (or natural or physical) legal properties is precisely what is asserted by legal positivists through the so-called social thesis, which has it that we determine what the law is using factual criteria (on the social thesis, see section II). That is to say, if the analyst succeeds in establishing that the property of being law is a descriptive property, he would seem to have offered at least some support for the social thesis of legal positivism and, therefore, for legal positivism.

In order to investigate this interesting question, I shall carry out a Canberra-style analysis of the concept of law, and I shall argue, tentatively, (1) that $X$ is law if, and only if, (i) $X$ is a relation between $(\alpha)$ a system of norms all of which can be traced

\footnotetext{
2 On this topic, see, eg Quine (1953), Harman (1999), Leiter (2007: 121-35), or Spaak (2016) with further references.

3 See, eg Braddon-Mitchell and Nola (2009).

4 I will explain what I mean, or rather what Frank Jackson means, by a 'descriptive' property in section IV.
} 
back to one of several recognised sources of law that can be handled on the basis of exclusively factual considerations, and $(\beta)$ an organization that is constituted and regulated by the norms of the system and whose task it is to interpret and apply these norms; (ii) $X$ aspires to regulate social life in general; (iii) $X$ is nonoptional; and (iv) $X$ claims to trump competing normative systems. In addition, I shall argue, equally tentatively, (2a) that the property of being law is precisely the descriptive property that satisfies the conditions (i)-(iv), (2b) that this property is a role property, not a realiser property, and (2c) that there is very little to be said about the legal realiser property on a general level and that the legal realiser property differs in this regard from moral and mental realiser properties.

I shall, however, also argue (3a) that the analyst who applies the Canberra Plan to the concept of law will almost certainly find it very difficult to come up with a collection of sufficiently rich analytic platitudes, especially what Frank Jackson calls input and output clauses, (3b) that he is not likely to get much help from the idea of mature legal thinking (introduced here as an analogue to Jackson's idea of mature folk morality), and (3c) that the so-called permutation problem, which is very problematic, will arise as a result of the above-mentioned lack of input and output clauses. And I shall therefore argue (4) that, as things stand, the Canberra Plan will not help us clarify the nature of law or lend support to the strong social thesis of legal positivism.

I shall approach the Canberra Plan mainly, but not exclusively, through Frank Jackson's writings on the subject. I begin, however, with a few words about legal positivism and about the connection I see between the social thesis and the idea that the property of being law is a descriptive property (section II). I continue by introducing Jackson's idea that serious metaphysics requires conceptual analysis and that conceptual analysis should be modest (sections III, IV) and then turn to a consideration of the idea behind and the steps involved in the Canberra Plan and of some of the advantages and disadvantages of the Plan (sections V-XII). Having done that, I analyse the concept of law using the Canberra Plan (section XIII) and add some thoughts on the idea of mature legal thinking (section XIV). I reiterate my conclusions in section XV.

\section{Legal Positivism}

As I see it, legal positivism is a theory of law (in a wide sense of the term 'theory'), not a theory telling the judge how he should decide hard cases or when civil disobedience is justified. What legal positivism does is to lay down conditions that have to be satisfied by anything that purports to be law. We might say that legal positivism is a meta-theory of law, in the sense that it aims to lay down requirements that any adequate theory of law must meet (see Raz 2009 [1979]: 39). On this analysis, a legal positivist theory of law, such as Kelsen's theory or Hart's theory, may be called a first-order theory of law that is also a legal positivist theory 
in the sense that it conforms to the main theses of legal positivism (to be discussed below) conceived as a second-order theory of law.

Legal positivists such as John Austin (1998), Hans Kelsen (1960; 1999), HLA Hart (1961; 1982), Neil MacCormick and Ota Weinberger (1986) and others differ on a number of issues, but they all accept three central tenets, namely the social thesis, the separation thesis, ${ }^{5}$ and (what I shall refer to as) the thesis of social efficacy. In addition, some legal positivists accept a fourth thesis, namely the semantic thesis. Crudely put, the social thesis has it that we can determine what the law is using factual criteria; the separation thesis has it that there is no necessary (in my interpretation, no conceptual) connection between law and morality; the thesis of social efficacy has it that the validity (or existence) of law presupposes that it is efficacious; and the semantic thesis has it that central normative terms such as 'right', 'duty' and 'ought' have a special legal meaning (sense), which differs from the meaning they have in a moral context. ${ }^{6}$

Since it is clear that the social thesis is of special interest in this context, we should consider it more closely. Let us therefore note that legal positivists disagree about how to understand it. While some argue that, properly understood, it requires the use of exclusively factual criteria of legal validity, and that any reference to moral values is best understood as granting the judge discretion to create new law, ${ }^{7}$ others maintain that the criteria of validity may, but need not, to some extent be of a moral nature, as long as they are grounded in facts. ${ }^{8}$

Now given that legal positivists hold that the social thesis is true, that we can determine what the law is using factual criteria, it seems reasonable to assume that if we were to apply the Canberra Plan to central legal concepts, such as the concept of law, the concept of a legal norm, or the concept of a legal duty, and if we managed to establish that the corresponding legal properties are indeed descriptive, we would have some reason to infer that the social thesis is true. We need, however, a better understanding of the relation of support. First, we should focus on the above-mentioned strong social thesis, according to which we can determine what the law is using exclusively factual criteria. For if the relevant criteria can be to some extent moral, we have no good reason to expect that legal properties should be descriptive. Secondly, we need to be clear about whether we mean to argue (i) that if we can determine what the law is using exclusively factual criteria $(A)$, then the relevant legal properties are descriptive $(B)$; or (ii) that if the relevant legal properties are descriptive $(B)$, then we can determine what the law is using exclusively factual criteria $(A)$; or (iii) $(A)$ if and only if $(B)$.

To be clear about the second point is especially important. If the result of the analysis is that legal properties are descriptive, $(B)$, and if $(A) \supset(B)$ is the case,

\footnotetext{
5 Joseph Raz does not accept the separation thesis. See Raz (2009: 38-39).

6 On these four theses, see Spaak (2014: 244-53).

7 See Raz (1986: 1110); also Leiter (2007: 121-35).

8 See Coleman (2001: chs 6-10); also Hart (1994: 247-48, 250-51) and Waluchow (1994).
} 
then we have nothing more than a case of affirming the consequent. That is, we will at the most have given some inductive evidence for (A), the strong social thesis. If, on the other hand, the result of the analysis is that legal properties are descriptive, $(B)$, and if $(B) \supset(A)$ holds, then we can conclude (A), that the strong social thesis is true. For this would be an application of the rule of modus ponens. The question, then, is whether it follows from the truth of the strong social thesis, if it is true, that legal properties are descriptive, or whether it follows from the fact, if it is a fact, that legal properties are descriptive that the strong social thesis is true, or both. I am inclined to hold both that if we can determine what the law is using exclusively factual criteria, then legal properties are descriptive, that is, (A) $\supset$ (B), and that if legal properties are descriptive, then we can determine what the law is using exclusively factual criteria, that is, (B) $\supset$ (A). In other words, I am inclined to hold that $(A)$ if, and only if, $(B)$.

The claim that a finding that legal properties are descriptive properties would support the strong social thesis is not airtight, however. For one thing, one might object that while a legal positivist like Kelsen (1965: 465) accepts, or would accept, the strong social thesis, he certainly does not believe that legal properties are descriptive. ${ }^{9}$ Does Kelsen's position qualify as a counterexample to the claim $(\mathrm{A}) \supset(\mathrm{B})$, that if we can determine what the law is using exclusively factual criteria, then legal properties are descriptive? I do not think so. On Kelsen's view, the non-natural status of legal properties is a direct result of the introduction of the theory of the basic norm, and this rather problematic theory adds a very important component to Kelsen's analysis, namely the presupposition that legal norms are binding in a strong moral sense.

One could, however, also object that there is available an alternative explanation of the fact, if it is a fact, that legal properties are factual properties. For one might argue that if some naturalist version of natural law theory, or, more broadly, non-positivism, is true, then this would explain why and how legal properties are natural properties. Indeed, as far as I can tell, Michael Moore (2002) defends precisely such a naturalist version of non-positivism. ${ }^{10}$ If Moore's theory were defensible, we would have to conclude either that the strong social thesis is not unique to legal positivism (since Moore appears to embrace it) or else that we are not entitled to infer that the strong social thesis is true from the sole premise that legal properties are descriptive.

I accept the logic of the objection, though I have doubts about the truth of moral naturalism. Note here that one does not have to accept moral naturalism in order to accept legal naturalism (or legal descriptivism). What I am considering in this chapter is the plausibility of the claim that legal properties are descriptive, and this is prima facie a more plausible claim than the claim that moral properties are

9 See Kelsen (1992: 12).

10 Dworkin (2006: 147-56) proposes that we think of the content of legal and political concepts by analogy to the way we think of the content of natural kind concepts. His idea is discussed in an illuminating way by Patterson (2006). 
descriptive (or natural) properties. For it is quite clear that law is in an important sense a social institution.

I therefore conclude, with these qualifications, that the Canberra Plan can be used to underpin the strong social thesis of legal positivism, provided (a) that the Plan turns out to be defensible when applied to legal concepts and $(b)$ that the result of the analysis is that legal properties are descriptive. Condition $(a)$ is obviously important, but so is condition $(b)$. For the Canberra Plan does not in any way guarantee that there will actually be a descriptive property corresponding to the concept that has been analysed.

\section{Serious Metaphysics and Conceptual Analysis}

In his influential book From Metaphysics to Ethics: A Defence of Conceptual Analysis (1998), Frank Jackson defends the method of conceptual analysis against criticism. He argues, persuasively in my view, that the criticism is premised partly on a misunderstanding of what it is to engage in conceptual analysis, and partly on a failure to appreciate just how indispensable conceptual analysis, properly understood, really is. He maintains, more specifically, that (what he refers to as) serious metaphysics requires conceptual analysis, though he is careful to point out that conceptual analysis should play a modest role in philosophical thinking, in the sense that it should concern not the question of what the fundamental nature of the world is like, but the question of what to say about the world in a certain language, given an account of the world in a more fundamental language.

Jackson explains ${ }^{11}$ that metaphysics attempts to account for what there is in a privileged, fundamental language, such as the language of physics, and that we need to engage in conceptual analysis in order to become clear about precisely what is said in the less fundamental language, such as the language of psychology. If we do not know what, exactly, is said in the less fundamental language, if we cannot tell whether or not we should refer to the phenomenon we are faced with as, say, an instance of knowledge, meaning, binding force, etc, we will not be able to determine whether the theory formulated in the more fundamental language really accounts for what is said in the less fundamental language, that is, we will not be able to determine whether or not the analyst has succeeded in offering, say, a naturalist account of meaning or of the binding force of law. In the words of Jackson:

[s]erious metaphysics requires us to address when matters described in one vocabulary are made true by matters described in another. But how could we possibly address this question in the absence of a consideration of when it is right to describe matters in the

11 See Jackson (1998: 28-31). 
terms of the various vocabularies? And to do that is to reflect on which possible cases fall under which descriptions. And that in turn is to do conceptual analysis. Only that way do we define our subject. ${ }^{12}$

Jackson points out that this means that serious metaphysics raises (what he calls) the location problem, that is, the problem of locating some less fundamental feature of the world, such as knowledge, meaning, binding force, etc within the framework of the more fundamental theory. That is to say, if you have come up with what you consider to be a complete account of the world (or part of the world) in terms of the language of physics, you will have to choose between either locating or else eliminating properties whose existence we assert or imply in the less fundamental language. As Jackson sees it, there is a place in the world for such properties if, and only if, they are entailed by the account of the world in the more fundamental language, and he refers to this idea as the entry by entailment thesis. ${ }^{13}$ Discussing the case of physicalism and psychological properties, he puts it as follows: ${ }^{14}$

A putative psychological fact has a place in the physicalists' world view if and only if it is entailed by $\Phi$ [a claim formulated in physical terms]. Any putative psychological fact which is not so entailed must be regarded by the physicalist as either a refutation of physicalism or as merely putative.

To take a jurisprudential example, Scandinavian realist Karl Olivecrona (1939: chs 1,2$)$ argues that there are no binding legal rules because there is no such thing as binding force, though he also maintains that there are indeed non-binding legal rules in the shape of what he calls independent imperatives, which, although they lack binding force and therefore the capacity to establish legal relations, can influence the subjects of law (the citizens) on the psychological level and thus guide human behaviour. We might say that Olivecrona's metaphysical position is that an account of the world, including the world of law, in naturalist terms makes it clear that while there are no binding legal rules (elimination), there are indeed non-binding legal rules (location). We might thus say that, on Jackson's analysis, legal rules in the shape of independent imperatives have a place in the metaphysical framework of naturalism defended by Olivecrona precisely because they are entailed by it.

Jackson (1998: 25) explains that he means by 'entails' not 'conceptually entails', but simply 'the necessary truth-preserving notion'. This does not, however, mean that he does not hold that one can infer a normative conclusion analytically from analytical and empirical premises. On the contrary, his idea is that one can reason as follows:

(P1) The concept of being required by a legal norm to perform an action is the concept that plays the legal duty role in the legal network (analytical, a result of the Canberra Plan analysis).

\footnotetext{
12 ibid 41-42.

13 ibid 5.

14 ibid 26.
} 
(P2) Smith is required by a legal norm to pay income tax (empirical, observation).

- (C) Smith has a legal duty to pay income tax (normative, a first-order legal claim). ${ }^{15}$

Here the normative conclusion follows analytically from the combination of an analytical premise, $(P 1)$, and an empirical premise, $(P 2)$.

\section{Modest Conceptual Analysis}

Observing that conceptual analysis is sometimes given a modest and sometimes an immodest role in philosophical thinking, Jackson points out that while conceptual analysis is important, indeed indispensable, it should be given a modest, not an immodest, role. The difference between modest and immodest conceptual analysis, he explains, turns on the difference between (a) saying something in a less fundamental language about how we should classify certain facts, and (b) saying something in a more fundamental language about the fundamental nature of the world:

the role for conceptual analysis that I am defending in these lectures is the modest role: the role is that of addressing the question of what to say about matters described in one set of terms given a story about matters in another set of terms. Conceptual analysis is not being given a role in determining the fundamental nature of our world; it is, rather, being given a central role in determining what to say in less fundamental terms given an account of the world stated in more fundamental terms. ${ }^{16}$

Note that what Jackson is saying is that the fundamental nature of the world is described (or explained) by the more fundamental theory, say, a theory of physics, and that while the less fundamental theory, say, a psychological theory or a theory of law, does concern the world, it does not concern the fundamental nature of the world. For example, an epistemologist who has given an account of what he takes to be an interesting phenomenon in terms of the concepts 'true', 'justified' and 'belief' will also have to ask himself whether he is willing to think of this phenomenon as knowledge. On Jackson's analysis, the claim about true justified belief has been formulated in a more fundamental language, though certainly not in the language of physics, and the question for the conceptual analyst is now to determine whether it is correct to refer to this phenomenon as 'knowledge' in the less fundamental language. If it is correct, then the analyst has been able to reduce knowledge to justified true belief and, in this sense, to locate knowledge within the framework of the more fundamental theory. In contemplating how to classify this phenomenon, the epistemologist is, as Jackson (1998: 44) puts it, 'addressing the

15 This is my example, not Jackson's.

16 ibid 44. 
question of what to say about matters described in one set of terms given a story about matters in another set of terms'.

Jackson also points out ${ }^{17}$ that while he disagrees in theory with Quine's critique of the analytic-synthetic distinction, ${ }^{18}$ he can agree with it in practice. The modest role he gives conceptual analysis makes it possible for the analyst to do conceptual analysis in much the same way as he would be doing if he paraphrased sentences in the way Quine (1960: 157-61, 224) contemplates. For, he explains, ${ }^{19}$ when Quine speaks about paraphrasing a sentence, $S_{1}$, into another sentence, $S_{2}$, he (Quine) is not after synonymy, but 'just approximate fulfillment of likely purposes of the original sentence.' For example, the analyst might attempt to mould a concept, $C_{2}$, that is sufficiently similar to a concept, $C_{1}$, that we already have and make use of but which, strictly speaking, is incoherent (here Jackson mentions the concepts of free will and of personal identity as examples) so that $C_{2}$ will be able to do more or less the same job as $C_{1}$ does (or is assumed to do). And to say that $C_{2}$ will be able to do more or less the same job as $C_{1}$ does is, of course, to say that $C_{2}$ will be able to fulfil approximately the likely purpose(s) of $C_{1}$.

\section{Jackson's Moral Functionalism I: The Idea}

Jackson is not content to speak of conceptual analysis in general terms, however, but he also engages in it, ${ }^{20}$ and this, of course, is where the Canberra Plan enters the picture. He sets himself the task to come up with a solution to the location problem for ethics and begins by assuming cognitivism, that is, the view that moral sentences are truth-apt in the sense that they are semantically able to have a truth value, ${ }^{21}$ and proceeds to argue that ethical properties are descriptive, ${ }^{22}$ and that we should focus our analysis on folk morality: if we did not focus on folk morality, he points out, we would not have much of an audience. ${ }^{23} \mathrm{He}$ is, however, careful to point out ${ }^{24}$ that he does not assume that there is a sharp semantic divide between descriptive and ethical terms, that we can think of descriptive terms somewhat loosely as terms that are given by a big list of terms that are generally considered to be descriptive, and that we can allow that any term, say 'cruel' or 'honest', that appears to be a borderline case can simply be taken off the list. So, on Jackson's analysis, a descriptive property is not necessarily a natural or a physical property.

17 ibid 44-46.

18 See Quine (1953).

19 See Jackson (1998: 45).

20 ibid chs 5-6.

21 ibid 113-14

22 ibid 117-29.

23 ibid 117-18.

24 ibid 120-21. 
Jackson does not offer any analysis of the concept of a descriptive property, however, but says only that he has in mind properties that people believe fall on the 'is' side of the is-ought divide or have in mind when they speak of factual or descriptive vocabulary or properties. ${ }^{25}$ That is to say, he assumes that we do think of some properties as being descriptive and of other properties as being non-descriptive and that we are justified in doing so, while admitting that there may well be borderline cases. As he puts it, ${ }^{26}$ ' $[\mathrm{m}] \mathrm{y}$ experience is that people either find the notion [of a descriptive property] under any of its various names relatively unproblematic, in which case further explanation is unnecessary, or else no amount of explanation is of any use'.

Jaap Hage (2016a; 2016b) would object to Jackson's reasoning, however, that the lack of a clear definition, or at least a clear characterisation, of descriptive properties is due to the disturbing fact that there are no descriptive, but only normative, properties, and that this is so because ultimately all types of fact (here Hage makes a distinction between objective facts, which are thought to be mind-independent, inter-subjective facts, which depend on consensus in the relevant population, and rule-based facts, which depend on the existence of rules) are language-dependent and therefore rule-dependent, and because rules are (necessarily) normative.

I am not too worried about this objection, however, because (i) I doubt that all types of fact, including what Hage calls 'objective facts', are language-dependent in any interesting sense, ${ }^{27}$ and because (ii) I do not believe that such languagedependence, assuming it to be a fact, would undermine the common-sense claim that as a matter of (objective, or consensus-based, or rule-based) fact there are judges and professors, cats and dogs, and trees and mountains, and that the properties of being a judge, or a professor, or a cat, etc are descriptive in the sense that one can determine whether they are present without having to make any value judgement or normative judgement, as we normally understand these types of judgement. Moreover (iii), it seems to follow from Hage's line of argument that the above-mentioned (disturbing) fact - that is, that there are no descriptive, but only normative, properties - would itself be a normative, not a descriptive, fact. And this suggests that either a normative fact is not a fact, in which case Hage's line of argument would be undermined, or else it is not very different from an ordinary (descriptive) fact, in which case the utility of the distinction between descriptive and normative facts would be cast in doubt. I shall therefore allow myself to assume that we can for most legal, moral or political purposes coherently make a distinction between descriptive and non-descriptive language and properties.

Jackson's claim that ethical properties are descriptive properties is based on the global supervenience thesis, $S$ (for all worlds $w$ and $w^{*}$, if $w$ and $w^{*}$ are exactly alike descriptively then they are exactly alike ethically) which he considers to be a priori

\footnotetext{
25 ibid 120.

26 ibid 120.

27 On this, see Boghossian (2006: ch 3) and Searle (1995: chs 7-8).
} 
true and necessary (and, therefore, uncontroversial), ${ }^{28}$ together with the thesissometimes referred to as Hume's dictum-that necessarily co-existent properties, such as the ethical property, $e$, and the descriptive property, $d$, are really one and the same property. ${ }^{29}$ So according to $S$, any claim about how things are ethically is equivalent to some claim about how things are descriptively, and Jackson reasons that this, together with Hume's dictum, means that ethical properties are descriptive properties. For, he reasons, ${ }^{30}$ it follows from $S$ that it is a consequence of the way the ethical supervenes on the descriptive that any claim about how things are made in an ethical vocabulary makes no distinctions among the possibilities that cannot in principle be made in purely descriptive vocabulary'. And given Hume's dictum, the above conclusion - that ethical properties are descriptive propertiesfollows. He adds ${ }^{31}$ that it is clear from the a priori nature of supervenience, 'that it is part of our very understanding of ethical vocabulary that we use it to mark distinctions about the descriptive way things are'.

I find Jackson's argument plausible, if not compelling, though I note that while the supervenience claim is generally accepted by philosophers, the same cannot be said about Hume's dictum. ${ }^{32}$ I shall assume, for the purposes of this chapter, however, that Jackson is right to say that ethical properties are descriptive.

Jackson then turns to consider the question that he is really interested in, namely the question of which moral properties are which descriptive properties. ${ }^{33}$ In doing that, he introduces and defends a theory he calls moral functionalism, whose aim is to establish analytical connections between moral and descriptive predicates. Pointing out that moral functionalism is parallel to so-called common-sense functionalism in the philosophy of mind, ${ }^{34}$ he explains that the idea in both cases is (i) to elucidate the import of a given concept by placing it in a network of concepts, principles and opinions and identifying the role it plays in the network, and (ii) to identify the descriptive property, if any, that corresponds to the concept thus analysed. ${ }^{35}$ As he puts it, ${ }^{36}$ the task of the analyst is to 'find the properties which are such that, going under their purely descriptive property names, they make the clauses of ... folk morality come out true (near enough), and then identify each ethical property with the corresponding descriptive property'.

We see, then, that if the analyst is interested in finding, say, the descriptive property that makes an action morally right, he is to begin by elucidating the import of the concept of a morally right action by reference to the role this concept plays in the folk morality network and then proceed to identify the descriptive property

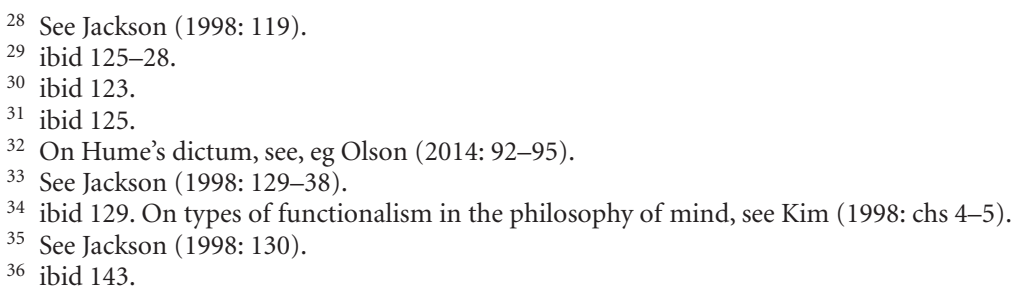


that makes an action morally right by investigating and seeing which descriptive property is always and necessarily at hand when we maintain (correctly), in keeping with folk morality, that an action is morally right.

According to Jackson, ${ }^{37}$ there are three components of the network of concepts, principles, intuitions and opinions that make up folk morality, namely (i) input clauses; (ii) internal role clauses; and (iii) output clauses. Some platitudes do service as input clauses and connect actions or situations described in descriptive, non-moral terms with actions or situations that are described in moral terms; other platitudes function as internal role clauses and connect actions or situations described in moral terms with other actions or situations also described in moral terms; and yet other platitudes function as output clauses and connect actions or situations described in moral terms with actions or situations described in descriptive, non-moral terms. As should be clear, while both input and output clauses connect the network and the world, they operate in opposite directions: whereas input clauses take us from the world to the network, output clauses take us from the network to the world. This difference is, of course, important.

Jackson then explains that moral functionalism differs from common-sense functionalism in two ways. ${ }^{38}$ First, unlike the principles of common-sense functionalism, the principles of moral functionalism are not causal principles, and, secondly, they are more controversial than the principles of common-sense functionalism. As regards the second point, Jackson observes that while there is considerable agreement about the principles of folk morality when broadly stated, the agreement tends to disappear when we consider the underpinnings of the principles, and he points out that this means that we tend to disagree to some extent about the application of the principles to concrete cases. As a result, the status of current folk morality is such that not even the roles of its central concepts, such as the concepts of a morally right or a morally wrong action, are sufficiently specified for the moral philosopher to be able to successfully carry out the moral functionalist programme.

For this reason, Jackson proposes that we should focus as moral functionalists on mature folk morality, that is, current folk morality as it would be if it had undergone a certain refinement: ${ }^{39}$ 'The idea is that mature folk morality is the best we will do by making good sense of the raft of sometimes conflicting intuitions about particular cases and general principles that make up current folk morality'. We see that Jackson's view is that we will be able to put our moral functionalism to good use when, but only when, folk morality has become sufficiently mature and rich to determine with precision the roles played by its concepts.

Jackson notes ${ }^{40}$ however, that current folk morality might not develop into one single mature folk morality, but might rather develop into several different

\footnotetext{
37 ibid 130-31.

38 ibid 131-32.

39 ibid 133.

40 ibid 137.
} 
mature folk moralities for different groups in the community, and that in such a case adherents of different folk moralities will necessarily mean to some extent something different by, say, 'right', 'wrong', 'cruel', 'honest', etc. This is reminiscent of the (radical) meaning variance that has been said to follow from the circumstance that so-called theoretical terms get their meaning holistically from their place in a given scientific theory. ${ }^{41}$ The underlying problem, of course, is that of incommensurability, that is, the impossibility of rationally comparing one folk morality (or one scientific theory) with another. While this problem may be even more disturbing in science, it must be considered to be a problem also in the fields of morality, politics and law. For moral, political and legal debates will not always be conducted between members of the same community (who, we assume, will share a moral network), but will occasionally involve members of different moral, political or legal communities. This is certainly true in the international, or global, arena today; and as the processes of globalisation proceed, with all that this involves regarding migration and increased international and transnational trade, such diversity is likely to become more and more pronounced.

\section{Jackson's Moral Functionalism II: Identifying the Descriptive Properties}

Jackson, as we have seen, is primarily concerned not with the analytical (or conceptual) question of elucidating the import of the concept under consideration, but with the question of identifying the descriptive property, if any, that corresponds to the concept, that is, with the metaphysical question of reducing a moral (psychological, semantic, legal, etc) property to a descriptive property. How, then, is the analyst to carry out such a reduction? According to Jackson, ${ }^{42}$ the analyst is to begin by spelling out (the claims of) folk morality in a long series of conjunctions with the moral predicates written in what he calls property-name style, as follows: 'The act of killing someone typically has the property of being wrong', 'Everything else equal, an equal distribution of goods typically has the property of being fair', or 'One's attitude to other people's belongings typically ought to have the property of respect'.

Having done that, the analyst is to continue by substituting a free variable for every distinct moral property term that occurs in a platitude. For example, the three platitudes just mentioned would be rewritten in the following way: 'The act of killing someone typically has the property $x$ ' and 'Everything else equal, an equal distribution of goods has the property $y$ ' and 'Respect stands in relation $o$ to other people's belongings'. This type of sentence, in which a free variable has been

41 On this, see, eg Newton-Smith (1981: ch 7).

42 See Jackson (1998: 140-41). 
substituted for the relevant moral (legal, semantic, etc) property term, has been referred to in the literature as a Ramsey sentence. ${ }^{43}$

The final step is for the analyst to turn this statement of conjunctions of platitudes featuring a free variable into an existential uniqueness claim in the following way: There are properties $x$ and $y$ (and $z$, $v$, etc) and a relation, $o$, (or relations $p, q$, etc), such that the act of killing someone typically has $x$, that everything else equal, an equal distribution of goods typically has $y$, and that respect typically stands in $o$ to other people's belongings, and for all properties $x^{\star}$ and $y^{\star}$ and relations $o^{\star}$, the act of killing someone typically has $x^{*}$, everything else equal, an equal distribution of goods typically has $y^{*}$, and respect typically stands in $o^{*}$ to other people's belongings if, and only if, $x=x^{\star}, y=y^{\star}$ and $o=o^{\star}$. This type of sentence has been referred to in the literature as a modified Ramsey sentence. ${ }^{44}$

In light of this analysis, we can now say, for example, that wrongness is the property $x$, such that there is property $y$ (or properties $y, z$, $v$, etc) and a relation, $o$, (or relations $o, p, q$, etc), that the act of killing someone typically has $x$, that everything else equal, an equal distribution of goods typically has $y$, and that respect typically stands in $o$ to other people's belongings, and for all properties $x^{*}$ and $y^{*}$ and relations $o^{*}$, the act of killing someone typically has $x^{*}$, everything else equal, an equal distribution of goods typically has $y^{*}$, and respect typically stands in $o^{*}$ to other people's belongings if, and only if, $x=x^{\star}, y=y^{\star}$ and $o=o^{\star}$.

What this means is that the import of the moral concept (or the meaning of the corresponding moral term) is determined by the role the concept (or the term) plays in the relevant moral network, so that an action, $A$, is wrong, or a distribution of goods, $D$, is fair, or an attitude to other people's belongings, $T$, is respectful, etc just in case $A$ has the property that plays the wrongness role, or $D$ has the property that plays the fairness role, or $T$ has the property that plays the respect role, etc in this moral framework. This, then, is the sense in which Jackson's moral functionalism is a species of functionalism.

\section{Jackson's Moral Functionalism III: Sense, Reference, and Realiser and Role Properties}

Jackson (1998: 143-44) is careful to point out that his moral functionalism is neutral on an interesting question, namely the question of whether we should think of the functionalist analysis (i) as determining the meaning (sense) of the relevant moral terms ('right', 'wrong', 'good', 'bad', etc); or (ii) as fixing the reference of these terms. In case (i) the term 'right', say, will function as a non-rigid definite

43 See, eg Braddon-Mitchell and Nola (2009: 2-4).

44 See, eg Lewis (1972: 253). 
description, that is, its referent may be $\alpha$ in our world and $\beta$ in another possible world, depending on what satisfies the definite description in the relevant world. As a result, a claim such as $(R)$ - an action, $A$, is right if, and only if, there is an $x$ such that $A$ has $x \ldots$ and for every $x^{\star} \ldots A$ has $x^{\star}$ if, and only if, $x=x^{\star} \ldots{ }^{45}$-will be both a priori and necessary. In case (ii), on the other hand, the analysis does not determine the meaning (sense) of 'right' but instead fixes its reference, so that if 'right' refers to $\alpha$ in our world, an action in another possible world that lacked $\alpha$ would not, and could not, be right. And as a result, $(R)$ will be a priori, but not necessary.

Moreover, as Jackson also points out, his moral functionalism does not itself tell us what the moral properties (rightness, wrongness, goodness, etc) are. He has told us a story about truth-conditions, he explains ${ }^{46}$ not a story about the metaphysics of rightness or wrongness, etc, and this story leaves open two possibilities, namely (i) that rightness (wrongness, goodness, etc) is the realiser property, that is, the first-order property that plays the rightness role; or (ii) that it is the role property, that is, the second-order property of having the property that plays the rightness role. ${ }^{47}$ Jackson's position is that we should take rightness (wrongness, etc) to be the realiser property, not the role property, and he offers the following argument in support of his view:

We want rightness to be what makes an action right, not in the causal sense but in the sense of being what ought to be aimed at. Now what we should aim at is not doing what is right qua what is right. I should rescue someone from a fire because if I don't they will die, not because that is the right thing to do. True, being motivated by an act's being right is better than being motivated by the desire to see one's picture in the papers. All the same, what ought to motivate us, and what we should value and pursue, is not the moral status of our actions per se, but the goods that confer that moral status. ${ }^{48}$

Discussing the property of moral rightness, Jackson proposes that we ask, first, what the essential feature or features of the rightness role are and, secondly, what property occupies that role. ${ }^{49}$ To illustrate the distinction, he contemplates the possibility that virtue theory supplies the answer to the first and utilitarianism the answer to the second question, so that the claim (i) that the property distinctive of the acts of the virtuous is rightness and the claim (ii) that the property distinctive of the acts of the virtuous is maximising expected utility would both be true. ${ }^{50}$ The difference between claims (i) and (ii), on this analysis, would be that the property of rightness is the role property, whereas the property of maximising expected utility is the realiser property.

45 See Jackson (1998: 143).

46 ibid 141.

47 For a helpful discussion of the distinction between realiser and role properties in the philosophy of mind, see Kim (1998: 116-19).

48 See Jackson (1998: 141).

49 ibid 142-43.

50 ibid 142. 
Although Jackson does not say so in this context, we should note that it is an attractive feature of any analysis of moral concepts that involves the distinction in question, that it can account for the existence of moral disagreement. ${ }^{51}$ For, on this type of analysis, while Smith and Jones might agree about the role property, say, that morally right acts are those that are characteristic of the virtuous person, they might nevertheless disagree about the realiser property, say, about whether this property is in fact the property of maximising expected utility or some other property. ${ }^{52}$ Clearly, this insight could be transferred to the legal case and could perhaps be invoked as an alternative to Dworkin's interpretive account of legal disagreement, ${ }^{53}$ though it seems clear that Dworkin's account has the advantage of having broader scope, in that it concerns theoretical disagreement in general, not only disagreement about the structure or import of concepts.

One may also wonder whether there is some kind of connection between the distinction between meaning-determination and reference-fixing, on the one hand, and the distinction between realiser properties and role properties, on the other, so that the analyst who opted for meaning-determination over reference-fixing, say, would have to go for realiser properties instead of role properties, or vice versa, on pain of inconsistency. Jackson does not, however, seem to think so. As we have just seen, he emphasises that his moral functionalism is neutral on the question of meaning-determination or reference-fixing, while defending the view that the descriptive properties are to be understood as realiser properties, and this appears to mean that he thinks we can combine the alternatives any way we want. For if he had believed that choosing meaning-determination required that descriptive properties be understood as realiser properties and that choosing reference-fixing required that descriptive properties be understood as realiser properties, he would not have needed to offer a separate argument (see the quotation above) in support of the view that the descriptive properties are to be thus understood.

\section{Michael Smith on the Network Model}

Although Michael Smith ends up rejecting the Canberra Plan, which he refers to as the 'network model', as applied to colour concepts and moral concepts, he offers

\footnotetext{
51 I would like to thank Åsa Wikforss for drawing my attention to this aspect of Jackson's analysis.

52 Could one also imagine a situation in which the parties agree about the realiser property but disagree about the role property? I think so. Consider the property of being an act of discrimination or of being a democracy. One could perhaps argue that whereas people agree about quite a few, but by no means all, instances of discrimination or democracy, most of us have rather hazy ideas about the import of the relevant concepts. Adopting a Canberra-style analysis, we might therefore say that while people agree to a significant extent about the realiser property of discrimination or democracy, they disagree about the role property. If this is a fair description, a Canberra-style analysis could perhaps illuminate such agreements (and disagreements) as well. Thanks to Jaap Hage for drawing my attention to the example of democracy.

53 See Dworkin (1986: chs 1-2).
} 
an illuminating account of it in his book The Moral Problem (1994: 44-47), which it will be worth our while to consider.

Having explained what he takes a platitude to be and why the analyst should focus on platitudes, ${ }^{54}$ Smith proceeds to list a number of platitudes that concern different aspects of morality, ${ }^{55}$ such as platitudes in support of the idea that morality is practical ((i) 'if someone judges her $\Phi$-ing to be right, then, other things being equal, she will be disposed to $\Phi$ '; (ii) 'weakness of will, compulsion, depression and the like may explain why someone isn't moved in accordance with her moral beliefs'); platitudes in support of the idea that morality is objective ((iii) 'When A says that $\Phi$-ing is right, and B says that $\Phi$-ing is not right, then at most one of A and B is correct'; (iv) 'Whether or not $\Phi$-ing is right can be discovered by engaging in rational argument'); and platitudes in support of the idea that moral properties supervene on natural properties ((v) 'acts with the same ordinary everyday nonmoral features must have the same moral features as well'). He adds platitudes concerning the substance of morality ((vi) 'right acts are in some ways expressive of equal concern and respect'; (vii) 'right acts are often other-regarding'); and platitudes concerning the procedures with the help of which we can discover which acts are right ((viii) 'arguments concerning rightness have a certain characteristic coherentist form').

Unlike Jackson, Smith does not speak of input clauses, internal role clauses and output clauses, but we might perhaps think of platitudes (v) and (vii) as rather weak input clauses, of platitude (vi) as an internal role clause, and of platitudes (i) and (ii) as rather weak output clauses. Unfortunately, I am unable to classify platitudes (iii), (iv) and (viii) in this regard, inter alia, because meta-claims, such as claims about the shape or structure of moral arguments, do not seem to fit Jackson's description of the clauses very well. One may, of course, wonder whether this lack of fit means that Smith's collection of platitudes is unsatisfactory, or that the distinction between these types of clause is unimportant. I am inclined to think that the distinction is important and that Smith's collection of platitudes is therefore not satisfactory. For, as we shall see (in section XI), the absence of input and output clauses will generate the very troublesome permutation problem.

In any case, Smith proceeds to offer a recipe for analysing a concept using the network model. And although it really does not add much substance to Jackson's account of the Canberra Plan, it is more elaborate and much easier to follow. For this reason, I shall consider it in some detail. Having first collected a number of appropriate platitudes surrounding the concept to be analysed (step 1), the analyst is to rewrite the platitudes so that the moral terms that feature in the platitudes occur in property-name style (step 2). For example, ${ }^{56}$ if someone judges her $\Phi$-ing to be right, then, other things being equal, she will be disposed to $\Phi$ ' becomes 'if

\footnotetext{
54 I will consider Smith's views on these topics in section X.

55 See Smith (1994: 30-40).

56 ibid 45.
} 
someone judges her $\Phi$-ing to have the property of being right, then, other things being equal, she will be disposed to $\Phi$ '; 'right acts are in some ways expressive of equal concern and respect' becomes 'acts that have the property of being right have the property of being in some ways expressive of equal concern and respect'; and 'right acts are often other-regarding' becomes 'acts that have the property of being right are often other-regarding'.

Next, the analyst is to write down a long conjunction of the reformulated platitudes and substitute a freevariable for each distinct moral property term (step 3). For example, 'if someone judges her $\Phi$-ing to have the property of being right, then, other things being equal, she will be disposed to $\Phi$ ', becomes 'if someone judges her $\Phi$-ing to have the property $x$ [that of being right], then, other things being equal, she will be disposed to $\Phi$ ', 'acts that have the property of being right are in some ways expressive of equal concern and respect' becomes 'acts with $x$ have the property y [that of being in some ways expressive of equal concern and respect]', and 'acts that have the property of being right are often other-regarding' becomes 'acts with $x$ are often other-regarding', etc. These, as we have seen, are the so-called Ramsey sentences.

When the analyst has done this, he can say (step 4) that if there are any moral properties at all, then there are certain properties, $x, y, z$, etc that play the relevant roles in the moral network, and that these properties are unique. We may with Smith ${ }^{57}$ express this idea in the language of predicate logic as follows (where $M$ is a moral predicate): $\exists x \exists y \exists z \ldots M[x, y, z \ldots] \&\left(\forall x^{\star}\right)\left(\forall y^{\star}\right)\left(\forall z^{\star}\right) \ldots M\left[x^{\star}, y^{\star}, z^{\star} \ldots\right]$ if and only if $\left(x=x^{\star}, y=y^{\star}, z=z^{\star}\right)$.

Finally, the analyst can say that the property of being right, say, is the $\mathrm{x}$ such that $\exists y \exists z \ldots M[x, y, z \ldots] \&\left(\forall x^{\star}\right)\left(\forall y^{*}\right)\left(\forall z^{*}\right) \ldots M\left[x^{\star}, y^{\star}, z^{\star} \ldots\right]$ if and only if $\left(x=x^{*}\right.$, $\left.\mathrm{y}=\mathrm{y}^{\star}, \mathrm{z}=\mathrm{z}^{\star} \ldots\right)$. And as Smith points out, this statement of conjunctions mentions no moral terms at all, and we may therefore, given certain plausible assumptions (see the quotation below), think of it as a naturalist analysis of moral terms:

no moral terms are needed to say what ' $\mathrm{M}$ ' means, for these were all stripped out and replaced by variables at an earlier point in the analysis. Rightness is rather characterized in terms of the relations it stands in to the other moral properties and to the other things mentioned in the platitudes: motivation, action, the circumstances of argumentation, acts of an other-regarding kind and the like. What we have here is therefore a definition of rightness in non-moral terms. Indeed, on the plausible assumption that the other things mentioned in the platitudes about moral properties are themselves natural features, it is a definition of the property of being right in entirely naturalistic terms. ${ }^{58}$

Note that whereas Jackson was concerned with descriptive terms (in the sense explained in section IV), Smith's focus is on naturalistic terms, which are included in, but do not exhaust, Jackson's category of descriptive terms. We see, then, that 
Smith aims to reduce moral properties to a narrower category of fundamental properties than does Jackson.

\section{Lewis on Defining Theoretical Terms}

Jackson points out ${ }^{59}$ that in developing his moral functionalism, he is really applying David Lewis's functionalist method of defining theoretical terms. ${ }^{60}$ Thus, discussing psychophysical identifications, Lewis (1972: 249) maintains that they are like theoretical identifications, such as the identification of water with $\mathrm{H}_{2} \mathrm{O}$, or light with electromagnetic radiation, and he explains that theoretical identifications in general are implied by the relevant theories, not just posited. The reason, he explains, ${ }^{61}$ is that the meaning of theoretical terms is determined by the causal role these terms play in the relevant theory.

Lewis illustrates the core idea of his functionalism in an informal way by telling an Hercule Poirot-like story about how a detective reconstructs a crime before an audience and in the process confers meaning on the arbitrary names he has introduced to refer to the co-conspirators. The detective, Lewis explains, tells a story about how three persons, whom he (the detective) tentatively names $X, Y$ and $Z$, conspired to murder another person, one Mr Body:

Seventeen years ago, in the gold fields of Uganda, $X$ was Body's partner ... Last week, $Y$ and $Z$ conferred in a bar in Reading ... Tuesday night at 11:17, $Y$ went to the attic and set a time bomb ... Seventeen minutes later, $X$ met $Z$ in the billiard room and gave him the lead pipe ... Just when the bomb went off in the attic, $X$ fired three shots in the study through the French windows. ${ }^{62}$

Observing that the story contains the names ' $X$ ' ' $Y$ ' and ' $Z$ ', which he refers to as T-terms (theoretical terms), Lewis points out that all we know about the meaning of the names is what we learn from the story itself, which also features other terms, called O-terms (because they are other terms). The meaning of the names (the T-terms), he explains, is determined precisely by the role they play in the story: ${ }^{63}$ "They [the names] were introduced by an implicit functional definition, being reserved to name the occupants of the three roles. When we find out who are the occupants of the three roles, we find out who are $X, Y$ and $Z$. Here is our theoretical identification'.

Lewis points out that in telling the story, the detective implied that the roles occupied by $X, Y$ and $Z$ were occupied, indeed, uniquely occupied, and that this

\footnotetext{
59 See Jackson (1998: 140).

60 See Lewis (1970: 1972).

61 ibid 249-50.

62 ibid 250.

63 ibid 251.
} 
means that we can think of the T-terms (' $X$ ', ' $Y$ ' and ' $Z$ ') as definite descriptions: ${ }^{64}$ 'If the story is uniquely realized, they name what they ought to name: if the story is unrealized, or multiply realized, they are like improper descriptions'.

I find this rather banal detective story illuminating. Just as the detective confers meaning on the names ' $X$ ', ' $Y$ ' and ' $Z$ ' by telling a (sufficiently rich) story about the bearers of the names, the Canberra Plan confers meaning on moral (legal, semantic, etc) property terms by telling a (sufficiently rich) story in the shape of a set of platitudes about the bearers (or referents) of those property terms, that is, the moral (legal, semantic, etc) properties. That is to say, just as the bearers of the names ' $X$ ' ' $Y$ ' and ' $Z$ ' are the three persons whose behaviours fit the detective story that features the names, the bearers of the moral (legal, semantic, etc) property terms are the descriptive properties that fit the moral (legal, semantic, etc) story that features the property names. As far as I can see, the core idea of the Canberra Plan is as simple as that, though, as we shall see in section XIII below, this is not to say that it is easy to analyse moral (or other) concepts pursuant to the Canberra Plan.

\section{Idea of a Platitude}

We have seen that the idea of a platitude plays an important role in the Canberra Plan. But, one wonders, what counts as a platitude for the purposes of the Canberra Plan, and why should the analyst focus on platitudes at all? Michael Smith has considered these questions. As he sees it: ${ }^{65}$

[t] o say that we can analyse moral concepts, like the concept of being right, is to say that we can specify which property the property of being right is by reference to platitudes about rightness ... by reference to descriptions of the inferential and judgemental dispositions of those who have mastery of the term 'rightness'.

The idea is that the inferential and judgemental dispositions of those who have mastery of the concept $X$ will be clear from the relevant platitudes, that the dispositions as revealed by the platitudes determine the role $X$ plays in the network, and that this role in turn determines the import of $X$ and therefore what, if any, descriptive property corresponds to $X .^{66}$ As we shall see below (in section XII), this is also the sense in which the Canberra Plan is a version of so-called responsedependent theories of moral (or other) judgements.

What, then, is a platitude? There does not seem to be an unequivocal answer to this question. But following Nolan (2009: 271-78), we may at least distinguish between a narrow and a broad conception of platitudes and think of these

64 ibid 252.

65 See Smith (1994: 39).

${ }^{66}$ For the sake of simplicity, I will mostly speak of determining the import of concepts (or the meaning of terms), but in doing so I do not intend to rule out reference-fixing. 
conceptions as being placed at opposing ends of a continuum. On the narrow conception, analytical (conceptual or logical) truths about or involving the relevant concept, and only such truths, count as platitudes. On the broad conception, not only analytical truths, but any clearly true empirical claim, about or involving the concept counts as a platitude.

Since the analyst's choice of platitudes will help determine the import of the concept he is analysing, he needs to be clear about what he takes a platitude to be, and why. Generally speaking, the closer the analyst stays to the narrow conception, the more his enterprise will resemble that of classical conceptual analysis, in that it will aim at establishing an analytical equivalence between analysandum and analysans, and the closer he stays to the broad conception, the more his enterprise will resemble that of an empirical investigation into the current and contingent use of concepts in the relevant community, and the more the import of the concepts under consideration will depend on substantive claims whose truth is accepted in the relevant community but perhaps not in other communities.

Smith stays close to the narrow conception. For he takes a platitude to be a statement that is considered to be obviously true by anyone who has mastery of the relevant concept because he has mastery of that concept ${ }^{67}$ Having taken colour concepts as his example and having listed a number of platitudes about colours ('most everything we see looks coloured', 'the colours of objects cause us to see the objects as coloured', 'there's no seeing a colour without seeing an extended colour patch', 'red is more similar to orange than to blue', etc) he states the following: ${ }^{68}$

The point is ... that these remarks [these platitudes] capture the inferential and judgemental dispositions vis-à-vis the word 'red' of those who have mastery of that term ... To have mastery of the word 'red' is to be disposed to make inferences and judgements along these lines.

To give up on the platitudes surrounding a concept is to give up on using the concept altogether, Smith explains, ${ }^{69}$ because the platitudes 'have a prima facie a priori status, and gain a priori status simpliciter by surviving as part of the maximal consistent set of platitudes constitutive of mastery of the relevant concept'. The platitudes, he reiterates, ${ }^{70}$ 'constitute the pattern of inferences licensed by our ... concepts'. And considering the possibility of including in the set of platitudes for colour terms such obviously true empirical claims as 'Red is the colour of blood' or 'Yellow is the colour of a new-born chicken', he points out that while these claims are indeed platitudes in one sense of the term, they are not platitudes in the relevant sense:

For though these claims are widely believed, they are still contingent and a posteriori truths about the colours, truths whose rejection, in relevant circumstances, would be

67 ibid 30.
68 ibid 30.
69 ibid 31.
70 ibid 31. 
neither here nor there with respect to whether or not we possess and are capable of using colour concepts. They are therefore not truths whose internalization is in any way constitutive of mastery of the colour terms. They do not constitute a statement of a set of inferences or judgments licensed by our colour concepts themselves. Thus, since it is not even prima facie a priori that red is the colour of blood, yellow is the colour of a new born chicken, and so on, we cannot use these platitudes to enrich our definitions of the colours. $^{71}$

I find Smith's account of platitudes appealing, though one may well wonder if the platitudes about colour that he proposes and that we considered above, such as 'most everything we see looks coloured', are really a priori. In any case, there seems to be a problem here. For we may safely assume that the closer the analyst stays to the narrow conception of platitudes, the harder it will be for him to find a sufficiently rich set of platitudes, especially input and output clauses. Thus Nick Zangwill (2000: 276-83) objects to Jackson's moral functionalism, which is more or less identical to Smith's network account, that there are in fact no, or very few, moral platitudes that could do service as input clauses in the relevant folk morality, because (Zangwill argues) on closer inspection all or almost all proposed platitudes turn out to be substantive moral claims, not conceptual moral claims. And the absence of conceptual platitudes would obviously be a big problem for the analytical moral functionalist, Zangwill points out, for the very aim of analytical moral functionalism is to establish precisely analytical connections between moral and naturalistic (or, more generally, descriptive) predicates via the role the moral concepts play in folk morality. ${ }^{72}$ I agree with Zangwill here. It does seem very difficult to come up with a sufficiently rich set of analytical platitudes in the field of morality. And, as we shall see (in section XIII), the same can be said about the situation in the legal sphere.

\section{The Permutation Problem}

Michael Smith has identified a problem with the network model, which he refers to as the permutation problem. ${ }^{73}$ He explains ${ }^{74}$ that the success of the model depends on the assumption that the relevant network can provide enough relational information to guarantee that there is a unique realisation of the network of relations. But, he notes, this may not always be the case. For example, certain concepts are part of such a tightly knit and interconnected network of concepts, claims and principles that the concepts are really defined in terms of one another. And in

\footnotetext{
71 ibid 51.

72 ibid 276.

73 See Smith (1994: 48-56).

74 ibid 48.
} 
such a case, the analyst will not be able to determine whether a given descriptive property, $\alpha$, corresponds to the one or to the other concept in the network.

Smith makes use of the example of colour concepts to illustrate the difficulty he has in mind and begins by assuming that we are interested in squaring our use of colour concepts with a broader physicalism, and that each colour occupies a certain place on a continuous colour wheel that determines the similarity relations between the colours. ${ }^{75} \mathrm{He}$ then collects a set of platitudes about the colour concepts, such as the following: ${ }^{76}$ the property of being red causes an object to look red to normal perceivers under standard conditions'; 'the property of being red is more similar to the property of being orange than it is to the property of being yellow'; 'the property of being orange causes an object to look orange to normal perceivers under standard conditions'; 'the property of being orange is more similar to the property of being yellow than it is to the property of being green'; 'the property of being yellow causes an object to look yellow to normal perceivers under standard conditions' and 'the property of being yellow is more similar to the property of being green than it is to the property of being blue'. Finally, he adds the assumption ${ }^{77}$ that there are no platitudes about colours 'that entail any claims beyond these about the properties of being red, or orange, or yellow, or the rest'. This is, of course, a very important assumption, because it means that there will be no other platitudes available that could help the analyst distinguish one colour property from another.

Next Smith ${ }^{78}$ draws our attention to the fact that the attempts to define the colour red, the colour orange, the colour yellow, etc all make reference to the very same network of relations and concludes that this means that 'we have lost any distinction between the properties of being red, being orange, being yellow and the rest'. The problem, he explains, ${ }^{79}$ is that the colour concepts 'are not defined in terms of enough in the way of relations between colours and things that are not themselves colours-or, at any rate, things that are not themselves characterized in terms of colours'. For this means that the colour wheel will not be anchored in reality, as it were, and this in turn means that the uniqueness requirement in the network analysis cannot be satisfied. Hence the analyst will not be able to carry out the second step of the analysis, that of identifying the different physical properties $(\alpha, \beta, \chi, \delta$, etc) that are thought to correspond to the respective colour concept. Smith therefore concludes ${ }^{80}$ that ' $\mathrm{t}$ ] horoughly explicit and reductive network analyses of our colour concepts lose a priori information about the differences between the colours. They are, therefore, defective, as analyses'.

\footnotetext{
75 ibid 48.

76 ibid $48-49$.

77 ibid 49.

78 ibid 50

79 ibid 55

80 ibid 50 .
} 
Having discussed colour concepts, he turns his attention to moral concepts and argues that they suffer from the same problem as do the colour concepts, that is, they are part of just such a tightly knit and interconnected network of concepts, principles and claims in which the concepts are really defined in terms of one another:

We learn all our normative concepts, our moral concepts included, inter alia by being presented with paradigms ... The platitudes surrounding our use of normative terms generally, and thus our moral terms as well, therefore form an extremely tight-knit and interconnected group. Such terms are largely interdefined. Perhaps the most striking way of bringing this out, in the case of moral terms, is by focusing on the various platitudes about procedure: that is, the various descriptions of the ways in which we justify our moral beliefs, what Rawls calls the 'method of reflective equilibrium'. For it is hard to believe that, once all normative terms are stripped out of these platitudes, there will be any determinate content left to them at all. And the loss of such content is just what makes for the permutation problem. ${ }^{81}$

I find the example involving colour terms, which are partly defined in terms of one another with the help of the colour wheel, persuasive and so accept that the analysis of colour terms does suffer from the permutation problem. I am not, however, convinced by Smith's brief discussion of moral terms. The problem with the analysis of the colour terms, as I see it, is that the place of a colour on the colour wheel partly defines the colour, because this means that the colours are partly defined in terms of one another. There does not, however, seem to be anything like a morality wheel in folk morality. And Smith's comment about Rawls's method of reflective equilibrium needs to be further elaborated, if one is to be able to assess it.

Nevertheless, one could argue that whether or not there is anything like the colour wheel in the relevant network, the permutation problem will arise in cases where (i) the platitudes are analytical, and (ii) where there are almost exclusively internal role clauses and therefore no, or very few, input and output clauses. For if the platitudes are analytical and if there are almost exclusively internal role clauses, the relevant concepts will be defined precisely in terms of each other, and this means that there will be no 'ground contact', that is, no connection between the network and the world. Hence the permutation problem.

But not everyone agrees that the permutation problem is likely to arise in the case of folk morality, at least not in the case of mature folk morality. James Lenman (2014: 42-43), for example, observes that in some cases the analyst might indeed be able to permute the relevant collection of platitudes in the sense that he might be able to substitute, say, the word 'wrong' for the word 'right', or the word 'good' for the word 'bad', and vice versa, and proceed to substitute variables in the usual way for these (and other) moral terms, thus arriving at a permuted Ramsey sentence. He then notes that such a permuted Ramsey sentence will be

81 ibid 55. 
awfully similar to the original, un-permuted Ramsey sentence, in which 'right' and 'wrong' and 'good' and 'bad' had not changed places, and this, of course, is to say precisely that we are here faced with the permutation problem. As he notes, ${ }^{82}$ '[c] ertain symmetries seem to exist in the structure of our moral concepts such that we can permute the place of the concepts in the structure in ways that allow for fatal underdetermination'.

$\mathrm{He}$ is, however, quick to point out that such permutation as there might be will very likely be undermined as soon as the analyst adds more platitudes to the collection. And he offers as an example the addition of a platitude such as 'virtuous people characteristically like to be surrounded by other virtuous people' and points out that the analyst can hardly permute this platitude without also undermining it. ${ }^{83}$ For, he notes, a claim like 'vicious people characteristically like to be surrounded by other vicious people' will not qualify as a platitude, since it is clearly false. He adds ${ }^{84}$ that Jackson's platitudes include substantive moral claims like it is wrong to betray friendship' and points out that one could hardly permute this claim into 'it is right to betray friendship' without also undermining it.

I do not find Lenman's examples convincing, however. If the analyst could allow himself to invoke non-analytical platitudes, like the ones suggested by Lenman, he would of course be able to undermine the symmetries that exist in the structure of our moral concepts and that allow for permutation. If, however, the analyst were to invoke non-analytical platitudes, he would as we have seen above (in section X) no longer be analysing concepts, but would rather be describing the current, and contingent, use of moral concepts. Hence it seems that the analyst who sticks with a collection of analytical platitudes will not be able to handle the permutation problem in the way Lenman suggests. ${ }^{85}$

I conclude that since it appears (i) to be very difficult to produce a sufficiently rich collection of analytical platitudes about or involving moral concepts, especially as regards input and output clauses; and (ii) that the presence of a number of analytical internal role clauses together with a dearth of input and output clauses will give rise to the permutation problem, any attempt to analyse moral concepts pursuant to the Canberra Plan will face considerable difficulties. And, as we shall see (in section XIII), the same holds for the analyst who concerns himself with the concept of law.

Let us now turn to consider another difficulty that any Canberra-style analysis of moral concepts will face, namely that the analysis tends to result either in a

82 See Lenman (2014: 43).

83 ibid 43.

84 ibid 44

85 I just said that Lenman says that Jackson's platitudes include substantive moral claims like 'it is wrong to betray friendship', and if this is so, Lenman's solution to the permutation problem will work. I note, however, that what Jackson (1998: 131-32) actually says is that this claim is a 'principle of folk morality' and that it is revisable. But can a platitude be revisable? Couldn't this mean instead that Jackson does not take it to be a platitude in the relevant sense? I am not sure and shall leave this an open question. 
change of the subject or in a trivial paraphrase of the moral judgement (or moral concept) that is being analysed.

\section{Response-Dependent Theories: A Difficulty}

Simon Blackburn (1998: 104-19) considers the Canberra Plan in his discussion of so-called response-dependent theories, that is, theories that aim at analysing moral judgements or moral concepts in terms of actual human responses, such as attitudes and desires. The idea is that the nature of certain phenomena is to be found precisely in the responses from a certain group of persons to claims about or involving the corresponding concept. As Blackburn sees it, the aim of the Canberra Plan is precisely to analyse moral concepts in terms of the responses of people to claims about or involving such concepts, responses that find expression in the platitudes. And he explains that response-dependent theories can be analysed with the help of a schema of the following type: ${ }^{86}$ ' $X$ is good/right/justifiable if, and only if, [persons] are disposed to [reaction] under [circumstances]', where the analyst can vary the parameter within the brackets by choosing to focus on different groups of persons, different kinds of reaction or different kinds of circumstance.

Blackburn objects, however, that response-dependent theories of moral judgements tend to make one of two serious mistakes: ${ }^{87}$ either they analyse the moral judgement in empirical terms and therefore change the subject, or they analyse it in moral terms and thus remain within the moral perspective, and so offer no real analysis, but only a paraphrase. As he puts it, this type of theory must therefore navigate between two potential disasters, namely that of changing the subject (Scylla), and that of offering nothing more than a paraphrase of the judgement that is being analysed (Charybdis), and they tend to fail.

Since the Canberra Plan focuses on platitudes, the question here is whether the relevant platitudes are essentially empirical or essentially moral or whether (as the Canberra planners hope) the holism of the network can save the collection of platitudes from the horns of the dilemma by somehow countering any tendency of the platitude collection to move towards the one or the other horn. Blackburn objects, however, that the holism of the network will not be able to save a Canberra-style analysis. For, he reasons, it does not follow from the fact that some platitudes are empirical and some moral either (a) that each and every platitude in the collection becomes a little of both, or (b) that the collection as a whole in some other way becomes evenly balanced between the empirical and the normative/evaluative

86 See Blackburn (1998: 105).

87 ibid 106. 
sides, so that the analysis can avoid both changing the subject and offering a trivial paraphrase:

The Scylla/Charybdis problem applied to response-dependent approaches to the content of evaluative remarks is this. Is judging $\mathrm{X}$ to be fair saying that it does elicit some response from us?- - but that way lies Scylla. Is it saying that it justifies such a response?but that way lies Charybdis. Jackson and Pettit ingeniously negotiate the trap by providing a lot of both: some statements about what responses are elicited by the judgement (the metatheoretical side, in which the judgement's typical effects are noted), others about what arrangements justify description as fair. So we are, as it were, tossed from side to side of the strait guarded by Scylla and Charybdis. But that is not the same as a straight passage through it. ${ }^{88}$

I agree with Blackburn's criticism. The only possibility of saving the analysis I can think of would be to elaborate on the above-mentioned alternative (b), that the existence of a number of platitudes, some of which are empirical and some of which are normative or evaluative, would somehow make the collection of platitudes as a whole evenly balanced and thus capable of avoiding the horns of the dilemma. But I cannot quite see how this would happen.

I do not think Blackburn's critique need worry us, however. For it seems to me that while it would be applicable not only to a Canberra-style analysis of moral judgements, but also to such an analysis of some legal judgments (legal concepts), such as the first-order legal judgements that Smith has a legal duty not to assault his annoying neighbour, or that Jones has a legal right to speak freely about politically controversial questions, it is not applicable to most legal judgements involving the concept of law, such as, say, the legal judgements that law is by its very nature a system of norms, or that the German legal order satisfies the conditions for being a Rechtsstaat. The reason is that the concept of law typically occurs in judgements in the legal meta-language (more on this in section XIII), and that therefore it typically occurs not in normative or evaluative, but in descriptive, judgements. ${ }^{89}$ And since the analyst is in such cases not concerned to reduce a normative judgement to a descriptive judgement, the Scylla/Charybdis problem about either changing the subject or else offering a trivial paraphrase will not arise.

\section{The Concept of Law}

As we have seen (in section V), Jackson argues that moral properties are descriptive, on the grounds that this follows from the global supervenience thesis $S$ together with Hume's dictum. And it is tempting to reason as follows: If it is correct to say, as Jackson does, that for all worlds, $w$ and $w^{\star}$, if $w$ and $w^{\star}$ are exactly alike

88 ibid 116 (emphasis added).

${ }^{89}$ Of course, a legal meta-language does not have to be descriptive, but it often is. 
descriptively, then they are exactly alike ethically, then it must also be correct to say that if $w$ and $w^{*}$ are exactly alike descriptively, then they are exactly alike legally. And if this is so, we seem to have reason to accept not only moral cognitivism, but also what we might call legal cognitivism, that is, the claim that (first-order) legal judgements (or sentences) are truth apt, in the sense that they are semantically able to have a truth value. ${ }^{90}$

The supervenience argument is, however, rather more problematic in the field of law than in the field of morality, at least when seen from the standpoint of legal positivism. According to legal positivism, there is no necessary connection between law and morality, and this means that legal norms may be immoral, even grossly so. And if this is so, it follows that the legislature has the legal power to enact pretty much any statute it wishes to enact (assuming that it respects the constitution, which can be changed). The same cannot be said about the way judges interpret and apply the law, however. For it is quite clear that a judge cannot legally treat two actions or situations that are descriptively exactly alike in different ways, because to do so would be to flout the Rechtsstaat requirement of formal justice, that like cases should be treated alike. The distinction between what the legislature can do, on the one hand, and what judges can do, on the other hand, is relevant in this context, because it suggests that although the supervenience argument could probably be made to work on the level of the interpretation and application of the law, it will not work on the level of validity (or existence). And if the supervenience argument does not work across the board in the field of law, we cannot use it here.

But one could perhaps argue, more loosely, that the fundamental property of being a legal norm does seem to be a descriptive property, perhaps the property of being a norm that is traceable back to a source of law, and that it is therefore reasonable to assume that closely related properties, such as the properties of being law, of being a legal duty, and of being a legal right are also descriptive properties. In any case, I shall assume, for the purposes of this chapter, that legal cognitivism is a defensible metaethical position.

Turning now to consider the concept of law, I begin by observing that this concept does not occur very often in first-order legal thinking, that is, legal thinking concerning ordinary legal problems, such as the problems of determining the meaning of a statutory provision or the ratio decidendi of a case. Instead, it typically occurs in philosophical and other types of second-order legal thinking, that is, thinking about law or its place in society. We might say with Frändberg (2009: 2) that whereas first-order legal concepts are typically used to state (or express) the content of the law ('One has a legal duty to drive on the right-hand side of the road' or 'Smith has a legal right to practise his religion'), second-order legal concepts are typically used to handle the legal content ('to have legal competence is to have the possibility of changing a legal position by performing an act-in-the-law'

90 Clearly, not everyone would go along with this assumption. For example, Scandinavian realists Alf Ross (1958) and Karl Olivecrona (1971) espouse a non-cognitivist analysis of legal judgements, which flatly contradicts the assumption. 
or 'to have a legal right is to have a legally recognized choice'). What this means, of course, is that the concept of law typically occurs not in claims in the legal object language, but in claims in the legal meta-language, and this in turn is to say that it typically occurs not in normative or evaluative, but in descriptive, claims. As we saw (in section XII), this circumstance is of some interest when considering Simon Blackburn's critique of response-dependent theories of moral (or other normative or evaluative) judgements.

Let us now begin the analysis. The first step is to write down a long conjunction of platitudes in which the concept of law features together with some other legal and non-legal concepts. I propose the following conjunction of platitudes, which I shall refer to as $L_{1}$ : (i) if there is law, there is a system of norms; (ii) if there is law, there is an organisation that is constituted and regulated by the norms of the system and whose task it is to interpret and apply said norms; (iii) if there is law, the citizens do, on the whole, obey it; (iv) if an entity is a legal norm, it can be traced back to a source of law, such as legislation, precedent or custom, which can be handled on the basis of exclusively factual considerations; ${ }^{91}$ (v) some legal norms impose legal duties on the legal subjects (Rechtssubjekte); ${ }^{92}$ (vi) some legal norms confer legal powers on the legal subjects; (vii) law aspires to regulate social life in general; (viii) law is non-optional; and (ix) law claims to trump competing normative systems.

$L_{1}$ raises a number of questions. For example, does it reflect a narrow or a broad conception of platitudes, or are the platitudes rather a mixed bunch? And are the platitudes evenly distributed among input clauses, internal role clauses and output clauses? The answer to the first question is that all, or almost all, the platitudes in $L_{1}$ are analytical truths. ${ }^{93}$ The second question must, however, be answered in the negative. If we assume that input clauses in legal thinking connect situations or actions described in descriptive, non-legal terms and situations or actions described in legal terms, that internal role clauses connect situations or actions described in legal terms and other situations or actions also described in legal terms, and that output clauses connect situations or actions described in legal terms and situations and actions described in non-legal terms, we see that there are quite a few internal role clauses, but a shortage of input and output clauses. Indeed, I cannot find a clear case of either input or output clauses in $L_{1}$, though one might perhaps think of platitude (iii) as an output clause.

91 Precedent conceived as a source of law is a bit problematic in this respect. While it seems to be a factual matter which cases are precedents, one might argue that the determination of the ratio decidendi is not, strictly speaking, a factual matter. Consider in this regard Julius Stone's critique of the so-called Goodhart method in Stone (1959). For the Goodhart method, see Goodhart (1931). The underlying question here is whether we should think of the ratio of a case as (i) the case itself, or as (ii) an interpretation of the case. If we settle for (i), we face a problem. If instead we settle for (ii), we avoid the problem.

92 On the idea of a Rechtssubjekt, see Kelsen (1960: 133-34).

93 There is, of course, room for debate about the status of the platitudes. I shall, however, allow myself to proceed on the assumption that they are indeed analytical. 
Why are there so many internal role clauses and so few input and output clauses? The main reason, it seems to me, is that legal norms are not necessarily moral norms; that, as Kelsen (1992: 56) puts it, legal norms can have any content, so that the content of legal norms is more or less arbitrary seen from a moral point of view. More specifically, legal norms are neither necessarily morally binding nor necessarily motivating in the sense contemplated by motivational internalists, ${ }^{94}$ and this means that there will be no systematic connection between legal norms, on the one hand, and moral content or moral motivation, on the other. As a result, the analyst cannot easily produce either analytical input clauses or analytical output clauses. Hence he will be left with a collection of platitudes that consists mostly of internal role clauses.

The second step is to rewrite the platitudes in property-name style as follows, thus transforming $L_{1}$ into $L_{2}$ : (i) if something has the property of being law, there is a system of norms; (ii) if something has the property of being law, there is an organisation that is constituted and regulated by the norms of the system and whose task it is to interpret and apply said norms; (iii) if something has the property of being law, the citizens do, on the whole, obey it; (iv) if something has the property of being a legal norm, it can be traced back to something that has the property of being a source of law; (v) some entities that have the property of being a legal norm impose something that has the property of being a legal duty on those who have the property of being a legal subject; (vi) some entities that have the property of being a legal norm confer something that has the property of being a legal power on those who have the property of being a legal subject; (vii) that which has the property of being law aspires to regulate social life in general; (viii) that which has the property of being law is non-optional; and (ix) that which has the property of being law claims to trump competing normative systems.

The third step is to substitute a free variable for each distinct legal propertyname, $p, q, r, s, t$ and $u$, as follows, thus transforming $L_{2}$ into $L_{3}$ : (i) if something has the property $p$ (that of being law), there is a system of norms; (ii) if something has $p$, there is an organisation that is constituted and regulated by the norms of the system and whose task it is to interpret and apply said norms; (iii) if something has $p$, the citizens do, on the whole, obey it; (iv) if something has the property $q$ (that of being a legal norm), it can be traced back to something that has the property $r$ (that of being a source of law); (v) some entities that have $q$ impose something that has the property $s$ (that of being a legal duty) on those who have the property $t$ (that of being a legal subject); (vi) some entities that have $q$ confer something that has the property $u$ (that of being a legal power) on those who have $t$; (vii) that which has $p$ aspires to regulate social life in general; (viii) that which has $p$ is nonoptional; and (ix) that which has $p$ claims to trump competing normative systems.

The fourth step, finally, is to transform $L_{3}$ into $L_{4}$ by adding an existential claim that there are indeed properties $p, q, r, s, t$ and $u$ together with a clause according

94 On such internalism, see, eg Shafer-Landau (2003: ch 6). 
to which these properties are unique. There exist properties $p, q, r, s, t$ and $u$, such that the following holds: (i) if something has $p$ (the property of being law), there is a system of norms; (ii) if something has $p$, there is an organisation that is constituted and regulated by the norms of the system and whose task it is to interpret and apply said norms; (iii) if something has $p$, the citizens do, on the whole, obey it; (iv) if something has $q$ (the property of being a legal norm), it can be traced back to something that has $r$ (the property of being a source of law); (v) some entities that have $q$ impose something that has $s$ (the property of being a legal duty) on those who have $t$ (the property of being a legal subject); (vi) some entities that have $q$ confer something that has $u$ (the property of being a legal power) on those who have $t$; (vii) that which has $p$ aspires to regulate social life in general; (viii) that which has $p$ is non-optional; and (ix) that which has $p$ claims to trump competing normative systems

and

for every $p^{\star}, q^{\star}, r^{\star}, s^{\star}, t^{\star}$ and $u^{\star}$ (i) if something has $p^{\star}$, there is a system of norms; (ii) if something has $p^{*}$, there is an organisation that is constituted and regulated by the norms of the system and whose task it is to interpret and apply said norms; (iii) if something has $p^{*}$, the citizens do, on the whole, obey it; (iv) if something has $q^{*}$, it can be traced back to something that has $r^{*}$; (v) some entities that have $q^{*}$ impose something that has $s^{*}$ on those who have $t^{*}$; (vi) some entities that have $q^{*}$ confer something that has $u^{*}$ on those who have $t^{*}$; (vii) that which has $p^{*}$ aspires to regulate social life in general; (viii) that which has $p^{*}$ is non-optional; and (ix) that which has $p^{*}$ claims to trump competing normative systems - if, and only if, $p=p^{*}, q=q^{*}, r=r^{*}, s=s^{*}, t=t^{*}$ and $u=u^{*}$.

We can now say that if there are any legal properties at all, then something like the following must hold true: $\exists \mathrm{p} \exists \mathrm{q} \exists \mathrm{r} \exists \mathrm{s} \exists \mathrm{t} \exists \mathrm{u} \mathrm{L}(p, q, r, s, t, u) \&\left(\forall \mathrm{p}^{*}\right)\left(\forall \mathrm{q}^{*}\right)\left(\forall \mathrm{r}^{*}\right)$ $\left(\forall \mathrm{s}^{\star}\right)\left(\forall \mathrm{t}^{\star}\right)\left(\forall \mathrm{u}^{\star}\right) \mathrm{L}\left(p^{*}, q^{*}, r^{\star}, s^{\star}, t^{*}, u^{\star}\right)$ if, and only if, $p=p^{*}, q=q^{\star}, r=r^{\star}, s=s^{\star}, t=t^{\star}$ and $u=u^{*}$. That is to say, there are properties $p, q, r, s, t$ and $u$, such that they are related to each other and to the world in the way indicated in the long statement of platitudes, and if there appear to be other properties $p^{*}, q^{*}, r^{*}, s^{*}, t^{*}, u^{*}$, such that they are related to each other and to the world in the same way, then the latter properties are identical to the former.

So far so good. We must now ask, what does this tell us about the structure and content of the concept of law? The trick, of course, is to put together the platitudes in $L_{1}-L_{4}$, and if we do we get something like the following: $X$ is law if, and only if, (i) $X$ is a relation between $(\alpha)$ a system of norms all of which can be traced back to any one of several sources of law that can be handled on the basis of exclusively factual considerations and $(\beta)$ an organisation that is constituted and regulated by the norms of the system and whose task it is to interpret and apply these norms; (ii) $X$ aspires to regulate social life in general; (iii) $X$ is non-optional; and (iv) $X$ claims to trump competing normative systems.

This analysis can certainly be criticised. Robert Alexy (2002: 127), for example, proposes a definition of the concept of law, which (in a somewhat simplified form) says that law is a system of norms (1) that lays claim to correctness, (2) consists of 
the totality of norms that belong to a socially efficacious constitution and that are not unjust in the extreme, and (3) comprises the principles and other normative arguments on which the procedure of law-application must be based in order to satisfy the claim to correctness. From the standpoint of Alexy, my analysis will be found wanting, inter alia, because it does not make use of the concept of a claim to correctness or the concept of a socially efficacious constitution (or system of norms).

But let us assume, for the sake of argument, that my analysis provides us with an acceptable analysis of the concept of law. We must now ask, what, if any, descriptive property corresponds to the concept of law thus analysed, and what kind of property this is: a realiser property or a role property? As I see it, the property that corresponds to this concept is precisely the property that satisfies the conditions (i)-(iv), and this property is descriptive if, and insofar as, each of the abovementioned criteria is descriptive. But are they? I think so. One might be tempted to object that the interpretation and application of legal norms, mentioned in $(i \beta)$, is not a value-neutral, or descriptive, matter, since the choice between competing interpretive arguments in light of, among other things, an assessment of the likely consequences of a given interpretation and application will rather often, even typically, involve a choice between morally relevant values, such as predictability or legislative efficiency. ${ }^{95}$ And if this is so, one might be tempted to argue that the precise content, if not the existence, of the law will rather often depend on moral considerations.

This would not be a good objection, however. While it is true, as the objection has it, that the process of interpreting and applying legal norms to facts will rather often, even typically, involve moral considerations on the part of the law-applier, this is an empirical fact about the interpretation and application of the law. That is to say, the objection, properly understood, is not that the precise content-and still less the validity (or existence)—of a legal norm will depend on what is morally right or good, but that it will depend on what the judge thinks is morally right or good, or, perhaps, appropriate or reasonable, and this (that is, what the judge thinks about moral matters) is not a moral, but an empirical, matter. If we make a distinction between internal (or first-order) legal statements, sometimes referred to as propositions of law (object language), and external (or second-order) legal statements, sometimes referred to as propositions about law (meta-language), we may say that the objection fails because it mistakes external for internal legal statements. ${ }^{96}$ Since this so, the objection under consideration gives us no reason to doubt that the property of being law, that is, the property of satisfying conditions (i)-(iv), is a descriptive property.

As we have seen, Jackson makes a distinction between realiser and role properties and proposes that the analyst should focus in the moral case on the realiser

95 On this, see Spaak (2004).

96 On these distinctions, see Spaak (2014: 97-104). 
property, not the role property. Should we follow Jackson and focus on the realiser property instead of the role property? I do not think so. As I see it, it is natural to think of the descriptive property of meeting the criteria (i) -(iv) above as the role property. For it is the property that corresponds to the concept of law, as that concept is understood in light of the role it plays in the network of concepts, principles and claims that I call (current) legal thinking. And if the platitudes are analytic, it will be an analytic truth that this is the role property.

But if this is the role property, what is the realiser property? That is to say, what is the property that realises this role in various circumstances, say, in different countries and in the international arena, or at different times? I cannot see that there is much of interest to be said about the realiser property on a general level. To be sure, we have seen that that which meets the relevant criteria is necessarily something that is a relation between a system of norms and an organisation that is constituted by those norms and whose task it is to interpret and apply those norms, and that aspires to regulate social life in general, is non-optional, and claims to trump competing normative systems. But it is clear that one such entity, say, UK law, may differ in certain respects from another such entity, say, German law. For example, the norms of the two systems may differ in that there may be more enacted norms in one system and more customary norms in the other, or along the rule/principle dimension, identified by Dworkin (1978: 22-28) and others, or in terms of content and moral quality, or in that the one legal order but not the other accepts the doctrine of binding precedent, etc. Moreover, the organisations whose task it is to interpret and apply the norms of the systems may also differ as regards, say, the number of levels of courts or the existence of courts that deal exclusively with one area of law, such as tax law, labour law or constitutional law. ${ }^{97}$

What this means is that there seems to be no one property that is the realiser property in all circumstances, and there is therefore very little one can say on a general level about the realiser property. And this means that the property of being law appears to be different from moral properties, such as the property of being a morally right action, and from mental properties, such as the property of being in pain, in that there appears to be quite a lot to be said about the realiser property on a general level in the moral and in the mental, but not in the legal, case. ${ }^{98}$ The reason, I suppose, is that law, as distinguished from pain, is very much an artifact, not a natural phenomenon-I shall have to leave it an open question whether morality is best understood as an artifact or as a natural phenomenon.

\footnotetext{
97 Whereas there is only one Supreme Court in the UK legal order (Bankowski and MacCormick 1991: 359-60), there are six different Supreme Courts in the German legal order (Alexy and Dreier 1991: 73-74).

98 On mental properties, see, eg Kim (1998: chs 4-5).
} 


\section{Mature Legal Thinking}

We have seen that if you wish to analyse a legal concept pursuant to the Canberra Plan, you are to collect a set of platitudes about or involving this concept (and some other concepts) and use these platitudes to clarify the role the concept plays in the network of principles, concepts and opinions that I have called (current) legal thinking. When you are reasonably clear about the import of the relevant concept, you proceed to investigate and see what descriptive property, if any, corresponds to the concept. And having done that, you know what law, or a legal norm, or a legal duty, etc is both in the sense of knowing the import of the concept of law, or the concept of a legal norm, or the concept of a legal duty, etc and in the sense of knowing what, if any, descriptive property is the property of being law, or a legal norm, or a legal duty, etc.

The main problem, as I see it, is to find a sufficiently rich collection of platitudes, a collection that yields as much relational information as the analyst needs to be able to successfully elucidate the relevant concept. As the reader will remember, it proved quite difficult to produce a sufficiently rich collection of analytical platitudes about or involving the concept of law, especially input and output clauses. And, as I have said, the lack of input and output clauses is very troublesome, since it gives rise to the permutation problem.

This is, of course, disappointing. Frank Jackson maintains, however, as we have seen, that moral philosophers applying the Canberra Plan ought to focus on mature folk morality instead of current folk morality, because mature folk morality, and only mature folk morality, would be rich enough to yield the relational information that the analyst needs to elucidate the concept(s). Against this background, it seems natural to apply a similar line of reasoning to the legal case and say that, even though it seems difficult at present to become clear about the import of the concept of law, it would be easier if we were to focus instead on mature legal thinking.

What, then, is mature legal thinking? Jackson does not have a lot to say about mature folk morality, except that we should think of it as current folk morality, as it would be if it had undergone a certain refinement. It seems to me, however, that mature legal thinking would differ in an interesting way from mature folk morality: Whereas the latter would include a number of substantive moral norms and values, the former would primarily include concepts and norms concerning the creation, interpretation and application of the law, and very few substantive legal norms or values. In other words, the main normative content in the legal sphere is to be found in law itself, not in legal thinking, though it is clear that the network of legal thinking would also include pronounced normative elements, albeit of a more formal nature, such as the ideal of the Rechtsstaat (or the rule of law); the separation of powers doctrine; the principle of legality; the rule of lenity; and various views about the ranking of the interpretive arguments. 
In any case, I believe the invocation of mature legal thinking by the analyst would be problematic for at least three reasons. First, one might argue that in invoking mature legal thinking, the analyst would be arguing in a circle. Stephen Yablo (2000: 15-19) (and Lenman 2014: 44) have raised such an objection to Jackson's moral functionalism. Yablo points out that mature folk morality appears to be inherently evaluative in the sense that we do not seem to be able to determine whether we are really faced with an instance of mature folk morality, unless we think in terms of what moral standards are well thought-out or reasonable and perhaps morally acceptable, and that this means that the analysis would be premised on an initial and unreduced moral judgement about the existence of mature folk morality - if the analyst had not made that moral judgement, his analysis would not have gotten off the ground.

How serious is this problem? Well, if you aim to offer a descriptive, or a naturalistic, analysis of a moral concept, such as the concept of a morally right action, by way of clarifying the role this concept plays in mature folk morality, and if you are able to identify mature folk morality only by reference to moral considerations that have not already been 'descriptivised' or naturalised, your reduction of moral to descriptive (or natural) properties will be dependent on an unreduced moral judgement about the existence of mature folk morality. That is to say, the (purported) reduction of moral to descriptive properties will not have been carried through 'all the way down'. From the standpoint of reductionism, this is not acceptable.

The question now is whether we have reason to suspect that the analyst would be facing a similar problem in the legal case. I answer this question in the affirmative, though the problem might be less formidable in the legal than in the moral case. If, as I believe, mature legal thinking, too, is inherently evaluative, although more formal than substantive, then the identification of the descriptive properties, if any, that correspond to the relevant concepts would depend in this way on an initial unreduced evaluative judgement about the existence of mature legal thinking. As we have seen, this is not acceptable.

Secondly, I doubt that our current legal thinking will in fact develop into more mature legal thinking in the foreseeable future. As I see it, legal thinking involves moral thinking, at least as regards the interpretation and application of the law: the identification of legal norms, as we have seen (in platitude iv in $L_{1}-L_{4}$ ), can be carried out without regard to moral considerations. And to the extent that mature legal thinking involves moral thinking, the analyst will have to wait for folk morality to mature, and this will almost certainly take a long time, if it will happen at all.

Thirdly, if current legal thinking did develop into mature legal thinking, it would very likely be legal thinking that was relative to a certain legal community, and this in turn would almost certainly lead to problems of incommensurability. For, as we have seen (in section IV), on the functionalist analysis, the import of a concept will depend on the role the concept plays in the relevant network of 
concepts, principles and opinions. So if a certain concept (say, 'duty', 'right', 'power' or 'validity') played a somewhat different role in different networks, it would have a somewhat different import in the respective networks (and communities), which is to say that the members of different legal communities would mean something different by 'duty', 'right', 'power' or 'validity'. Such radical meaning variance might not be as much of a problem in law as in morality, or politics, or science, however, since most (but not all) legal debates concern questions that arise within a given legal order. ${ }^{99}$

Fourthly, if we think of mature legal thinking as being relative to a certain legal community, the question arises whether the conclusions we can draw from the analysis will be of any interest outside that specific community. More specifically, the question arises whether an inquiry into the nature of law that is premised on a network of legal thinking that is peculiar to, say, Sweden or Italy, will really be an inquiry into the nature of law, as distinguished from an inquiry into the nature of Swedish or Italian law. The problem here, of course, is that an inquiry into the nature of law is usually taken to be an inquiry that aims to establish the essential properties of law. ${ }^{100}$ And to say that a property, $p$ (say, coerciveness or normativity), is an essential property of an object, $O$ (say, law), is to say that $p$ is a necessary property of $O$, that $O$ has $p$ in all possible worlds where $\mathrm{O}$ exists, so that if it turned out that $O$ lacked $p$ in one or more possible worlds, $p$ would not be an essential property of $O$ or else that (what purports to be) $O$ would not be $O$. But even if $p$ is a property of Swedish, or Italian, law, it does not follow that $p$ is a property of, say, Canadian law, and if it is not, it cannot be an essential property of law.

\section{Conclusion}

I have discussed the Canberra Plan and have applied it to the concept of law. My aim in doing so was to investigate and see whether the Canberra Plan could help us clarify the nature of law and lend support to the strong social thesis of legal positivism. I have argued (1) that $X$ is law if, and only if, (i) $X$ is a relation between $(\alpha)$ a system of norms all of which can be traced back to any one of several sources of law that can be handled on the basis of exclusively factual considerations and $(\beta)$ an organisation that is constituted and regulated by the norms of the system and whose task it is to interpret and apply these norms; (ii) $X$ aspires to regulate social life in general; (iii) $X$ is non-optional; and (iv) $X$ claims to trump competing normative systems. I have also argued (2a) that the property of being law is precisely the property that satisfies conditions (i)-(iv), (2b) that this property is a role

\footnotetext{
99 EU law and international law, more generally, might be problematic in this regard.

100 See, eg Raz (2009: 24-26); also Dickson (2001: 15-20).
} 
property, not a realiser property, and $(2 \mathrm{c})$ that there is very little to be said about the legal realiser property on a general level and that the legal realiser property differs in this regard from moral and mental realiser properties.

If this analysis were defensible, it would clarify the nature of law and offer support for the strong social thesis of legal positivism. I have also argued, however, (3a) that the analyst who applies the Canberra Plan to the concept of law will almost certainly find it very difficult to come up with a collection of sufficiently rich platitudes, especially input and output clauses, (3b) that he is not likely to get much help from the idea of mature legal thinking, and (3c) that the very troublesome permutation problem will arise as a result of the lack of input and output clauses.

On the basis of the said, I conclude (4) that, as things stand, the Canberra Plan suffers from such a serious problem that, although appealing and interesting, it will not help us clarify the nature of law or lend support to the strong social thesis of legal positivism. The serious problem, of course, is the above-mentioned permutation problem, which arises as a result of the lack of input and output clauses. For, as we have seen in our efforts to analyse the concept of law Canberra-style, it is precisely input and output clauses, not internal role clauses, that are difficult to find.

\section{References}

Alexy, R (2002) The Argument from Injustice: A Reply to Legal Positivism (Oxford, Oxford University Press)

_ (2008) 'On the Concept and Nature of Law' 21 Ratio Juris 281

Alexy, R and Dreier, R (1991) 'Statutory Interpretation in the Federal Republic of Germany' in DN MacCormick and RS Summers (eds), Interpreting Statutes: A Comparative Study (Aldershot, Dartmouth Publishers)

Austin, J (1998) The Province of Jurisprudence Determined and the Uses of the Study of Jurisprudence, with an introduction by HLA Hart (Indianapolis, IN, Hackett)

Bankowski, Z and MacCormick, DN (1991) 'Statutory Interpretation in the United Kingdom' in DN MacCormick and RS Summers (eds), Interpreting Statutes: A Comparative Study (Aldershot, Dartmouth Publishers)

Blackburn, S (1998) Ruling Passions (Oxford, Oxford University Press)

Boghossian, PA (2006) Fear of Knowledge: Against Relativism and Constructivism (Oxford, Oxford University Press)

Braddon-Mitchell, D and Nola, R (2009) 'Introducing the Canberra Plan' in D Braddon-Mitchell and R Nola (eds), Conceptual Analysis and Philosophical Naturalism (Cambridge, MA/London, MIT Press)

Coleman, JL (2001) The Practice of Principle: In Defence of a Pragmatist Approach to Legal Theory (Oxford, Oxford University Press)

Dickson, J (2001) Evaluation and Legal Theory (Oxford, Hart Publishing) 
Dworkin, R (1978) Taking Rights Seriously, 2nd edn (London, Duckworth)

— (1986) Law's Empire (Cambridge, MA, Belknap Press) (2006) Justice in Robes (Cambridge, MA, Belknap Press)

Frändberg, $\AA$ (2009) 'An Essay on Legal Concept Formation' in JC Hage and $\mathrm{D}$ von der Pfordten (eds), Concepts in Law (Dordrecht, Springer)

Goodhart, AL (1931) 'Determining the Ratio Decidendi of a Case' 40 Yale Law Journal 161

Hage, J (2016) 'Facts, Values and Norms' in S Taekema, B van Klink and W de Been (eds), The Development of Law: Establishing Legal Facts and Norms Through Interdisciplinary Research (Cheltenham, Edward Elgar)

— (2016) 'Facts and Meaning' in J Stelmach, B Brożek and $Ł$ Kurek (eds), The Emergence of Normative Orders (Krakow, Copernicus Center Press)

Harman, G (1999) 'Doubts about Conceptual Analysis' in Reasoning, Meaning, and Mind (Oxford, Oxford University Press)

Hart, HLA (1961) The Concept of Law (Oxford, Clarendon Press) (1982) 'Legal Rights' in Essays on Bentham (Oxford, Oxford University Press) (1994) The Concept of Law, 2nd edn, with a Postscript edited by Penelope A. Bulloch and Joseph Raz (Oxford, Oxford University Press)

Jackson, F (1998) From Metaphysics to Ethics: A Defence of Conceptual Analysis (Oxford, Oxford University Press)

Kelsen, H (1960) Reine Rechtslehre [The Pure Theory of Law], 2nd edn (Vienna, Franz Deudicke)

— (1965) 'Was ist juristischer Positivismus?' 15/16 Juristenzeitung 465 (1992) Introduction to the Problems of Legal Theory (Oxford, Oxford University Press)

- (1999) General Theory of Law and State (Union, NJ, Lawbook Exchange)

Kim, Jaegwon (1998) Philosophy of Mind (Boulder, CO, Westview Press)

Leiter, B (2007) Naturalizing Jurisprudence (Oxford, Oxford University Press)

Lenman, J (2014) 'Moral Naturalism' in EN Zalta (ed), The Stanford Encyclopedia of Philosophy, Spring 2014 edn, plato.stanford.edu/archives/spr2014/entries/ naturalism-moral/

Lewis, D (1970) 'How to Define Theoretical Terms' 67 Journal of Philosophy 427 -(1972)'PsychophysicalandTheoreticalIdentifications'50AustralasianJournalof Philosophy 249

MacCormick, DN and Weinberger, O (1986) An Institutional Theory of Law (Dordrecht, Reidel)

Moore, MS (2002) 'Legal Reality: A Naturalist Approach to Legal Ontology' 21 Law and Philosophy 619

Newton-Smith, WH (1981) The Rationality of Science (London/New York, Routledge)

Nolan, D (2009) 'Platitudes and Metaphysics' in D Braddon-Mitchell and R Nola (eds), Conceptual Analysis and Philosophical Naturalism (Cambridge, MA/London, MIT Press) 
Olivecrona, K (1939) Law as Fact, 1st edn (Copenhagen, Munksgaard/London, Humphrey Milford)

- (1971) Law as Fact, 2nd edn (London, Stevens \& Sons)

Olson, J (2014) Moral Error Theory (Oxford, Oxford University Press)

Patterson, DM (2006) 'Dworkin on the Semantics of Legal and Political Concepts' 26 Oxford Journal of Legal Studies 545.

Quine, WVO (1953) 'Two Dogmas of Empiricism' in WVO Quine, From a Logical Point of View, 2nd edn (Cambridge, MA, Harvard University Press)

— (1960) Word and Object (Cambridge, MA, MIT Press)

Raz, J (1986) 'A New Link in the Chain' 74 California Law Review 1103

_ (1994) 'Authority, Law and Morality' in Ethics in the Public Domain: Essays in Law and Politics, revised edn (Oxford, Clarendon Paperbacks)

- (2009) The Authority of Law, 2nd edn (Oxford, Oxford University Press)

Ross, A (1958) On Law and Justice (Berkeley/Los Angeles, CA, University of California Press)

Searle, JR (1995) The Construction of Social Reality (New York, Free Press)

Shafer-Landau, R (2003) Moral Realism: A Defence (Oxford, Oxford University Press)

Smith, M (1994) The Moral Problem (Oxford/Cambridge, MA, Blackwell)

Spaak, T (2004) 'Legal Positivism and the Objectivity of Law' in P Comanducci and R Guastini (eds), Analisi e diritto (Turin, g. giappichelli editore)

- (2014) A Critical Appraisal of Karl Olivecrona's Legal Philosophy (Dordrecht, Springer)

_ (2016) [forthcoming] 'Schauer's Anti-Essentialism' 29 Ratio Juris

Stone, J (1959) 'The Ratio of the Ratio Decidendi' 22 Modern Law Review 597

Waluchow, WJ (1994) Inclusive Legal Positivism (Oxford, Oxford University Press)

Yablo, S (2000) 'Red, Bitter, Best' 41 Philosophical Books 13

Zangwill, N (2000) 'Against Analytical Moral Functionalism’ 13 Ratio 275 
